\title{
Intentions to receive individual results from whole-genome sequencing among participants in the ClinSeq study
}

\author{
Flavia M Facio ${ }^{1}$, Haley Eidem ${ }^{1}$, Tyler Fisher ${ }^{1}$, Stephanie Brooks ${ }^{1}$, Amy Linn ${ }^{1}$, Kimberly A Kaphingst ${ }^{2}$, \\ Leslie G Biesecker ${ }^{1}$ and Barbara B Biesecker ${ }^{\star, 1}$
}

Genome sequencing has been rapidly integrated into clinical research and is currently marketed to health-care practitioners and consumers alike. The volume of sequencing data generated for a single individual and the wide range of findings from wholegenome sequencing raise critical questions about the return of results and their potential value for end-users. We conducted a mixed-methods study of 311 sequential participants in the NIH ClinSeq study to assess general preferences and specific attitudes toward learning results. We tested how these variables predicted intentions to receive results within four categories of findings ranging from medically actionable to variants of unknown significance. Two hundred and ninety-four participants indicated a preference to learn their genome sequencing results. Most often, participants cited disease prevention as their reason, including intention to change their lifestyle behaviors. Participants held positive attitudes, strongly perceived social norms and strong intentions to learn results, although there were significant mean differences among four categories of findings $(P<0.01)$. Attitudes and social norms for medically actionable and carrier results were most similar and rated the highest. Participants distinguished among the types and quality of information they may receive, despite strong intentions to learn all results presented. These intentions were motivated by confidence in their ability to use the information to prevent future disease and a belief in the value of even uninterpretable information. It behooves investigators to facilitate participants' desire to learn a range of information from genomic sequencing while promoting realistic expectations for its clinical and personal utility.

European Journal of Human Genetics (2013) 21, 261-265; doi:10.1038/ejhg.2012.179; published online 15 August 2012

Keywords: whole-genome sequencing; individual results; attitudes and intentions

\section{INTRODUCTION}

Genome sequencing is increasingly being used in clinical research, primarily as an extension of ongoing efforts to identify the etiology of rare diseases. ${ }^{1,2}$ The availability of the technology has stimulated widespread efforts to explore the clinical utility of whole-genome sequencing (WGS). Yet, the breadth of genomic interrogation has led to debate regarding which, if any, of the results should be returned to research participants. ${ }^{3-5}$ There is little controversy about the return of aggregate results. It is highly desirable and a social good to inform participants about the scientific discoveries that emanate from the use of their samples/data. Their engagement strengthens the social contract between researchers and participants. In contrast, the return of individual results from research studies has provoked much debate. Receipt of individual results from WGS, to date, has been reported primarily using case examples of scientists who have chosen to learn their own sequence. ${ }^{6-8}$ At the National Institutes of Health, ClinSeq is a clinical study that aims to enroll a cohort of $>1000$ participants who consent to WGS and have a choice about what types of information they want returned to them. ${ }^{9}$ This longitudinal study provides a novel opportunity for baseline assessment of preferences to learn personal health-related information from WGS.
The volume of sequencing data generated for a single individual and the wide range of possible findings raise critical questions about the return of results and what types of findings end-users will value. Controversy exists about the extent of individual results that should be returned to research participants. Guidelines suggest that at a minimum, investigators have an obligation to return medically actionable research findings. ${ }^{10,11}$ Some consensus is emerging on an obligation of investigators, both moral and legal, to return certain 'incidental findings', those that may not relate to the primary research pursuit. ${ }^{12}$ Increasingly, the academic debate about these findings acknowledges that WGS blurs the distinction between primary and secondary variants, as all genomes harbor unknown or unexpected findings, challenging the notion of 'incidental.' ${ }^{13}$ Recommendations for return of individual WGS results have generally focused on the clinical utility of the results. ${ }^{11,14,15}$ Kohane and Taylor ${ }^{13}$ call for a new paradigm for return of findings from genome sequencing, which considers preferences of research participants who may be seeking to learn 'personal' information. By this, they mean health information that are valued, even when it may not be actionable or meet standards for clinical utility. They argue for improvement in our understanding of participants' perceptions of the value of 'personal' sequence

\footnotetext{
${ }^{1}$ Social and Behavioral Research Branch, National Human Genome Research Institute, National Institutes of Health, Bethesda, MD, USA; ${ }^{2}$ Division of Public Health Sciences, Department of Surgery, Washington University, St Louis, MO, USA

${ }^{*}$ Correspondence: Dr BB Biesecker, Social and Behavioral Research Branch, National Human Genome Research Institute, National Institutes of Health, 31 Center Drive, Room B1B36, Bethesda, MD 20892, USA. Tel: + 1301 496-3979; Fax: + 1301 480-3108; E-mail: barbarab@mail.nih.gov

Received 28 February 2012; revised 4 July 2012; accepted 11 July 2012; published online 15 August 2012
} 
Table 1 Categories of results from WGC as presented to participants

\begin{tabular}{|c|c|c|c|}
\hline Category A & Category $B$ & Category C & Category D \\
\hline $\begin{array}{l}\text { A gene variant that predisposes you to a } \\
\text { disease that can be prevented or treated. } \\
\text { For example, you could learn that you } \\
\text { have a gene variant, which means you } \\
\text { are more likely to develop colon cancer. } \\
\text { In this case, we may recommend that } \\
\text { you have colonoscopies more frequently. } \\
\text { Or you could learn that you have a gene } \\
\text { variant that causes very high cholesterol. } \\
\text { In this case, we may recommend that } \\
\text { you have your cholesterol checked more } \\
\text { often and to take medication to lower it. }\end{array}$ & $\begin{array}{l}\text { A gene variant that predisposes you } \\
\text { to a disease that cannot be prevented } \\
\text { or treated. } \\
\text { For example, you could learn that you } \\
\text { have a gene variant, which means you } \\
\text { are more likely to develop Alzheimer's } \\
\text { disease, a disease that cannot be } \\
\text { prevented or treated. }\end{array}$ & $\begin{array}{l}\text { A gene variant that does not affect your } \\
\text { health, but that may be important to the } \\
\text { health of other relatives, such as your } \\
\text { children. } \\
\text { For example, you could learn that you } \\
\text { have a variant in the gene that causes } \\
\text { hemochromatosis. } \\
\text { Hemochromatosis is a disease that causes } \\
\text { the body to absorb too much iron from the } \\
\text { diet. Over time, the extra iron can damage } \\
\text { organs and tissues in the body. Having a } \\
\text { variant in the gene that causes } \\
\text { hemochromatosis would not cause any } \\
\text { health problems for you. But if you were } \\
\text { to have had children with someone who } \\
\text { also had a variant in the same gene, } \\
\text { then your children could have } \\
\text { hemochromatosis. }\end{array}$ & $\begin{array}{l}\text { Uncertain gene variants, } \\
\text { meaning they may or may } \\
\text { not be important to your } \\
\text { health or the health of } \\
\text { your relatives. }\end{array}$ \\
\hline
\end{tabular}

information, aware that their views may differ from that of researchers. One source of support for their argument is the data reported by Kaufman et al, ${ }^{16}$ which described the public's views of participating in bio-banks, including a majority who would desire to learn findings 'even if there is nothing they could do about them'. Bollinger et $a l^{17}$ found similar results. Kohane and Taylor ${ }^{13}$ emphasize the need for continued research to identify participant preferences to receive results. Findings from a sample of ClinSeq participants can inform the discussion about the role of clinical and personal utility in the return of results from genome sequencing.

Our prior study on the motivations of 320 distinct subjects to participate in ClinSeq resulted in two non-overlapping majority responses to an open-ended question: a desire to further research (altruism) and another to learn about one's health (personal gain). ${ }^{18}$ These results suggested that among the ultimate cohort of $>1000$ participants, about half will choose to learn findings relevant to their own health. This expressed interest raised questions for us about the value of various categories of findings in shaping intentions to receive results. As such, we designed a study of a new sample of the ClinSeq cohort to capture preferences to receive results and attitudes toward learning individual results, perceptions of the views of valued others (called social norms) and their correlation with intentions to receive results within four distinct categories of findings. ${ }^{19,20}$ See Table 1 for the descriptions of each category.

The aim was to learn the relative perceived value of the different types of findings among the ClinSeq participants. Our hypothesis was that there would be significantly more positive attitudes, higher perceived social norms and thus intentions to receive individual results associated with treatable or preventable conditions than results in the other three categories. We further hypothesized that there would be less positive attitudes, lower social norms and fewer intentions to learn uninterpretable results than results in the other three categories. Our study offers insight into the value that end-users place on the diverse findings from WGS.

\section{METHODS}

Three hundred and eleven consecutive individuals enrolled in the ClinSeq pilot-study-completed surveys between January 2009 and May 2011. The goal of ClinSeq has been to sequence most or all regions of 1000 human genomes. The initial focus of the study was on atherosclerotic heart disease but a majority are healthy volunteers. All participants were consented for interrogation of all genes and phenotypes. A description of the original ClinSeq cohort and study design is published. ${ }^{9}$ Since that publication, the study has generated exome sequence data for most participants. ${ }^{21}$ The National Human Genome Research Institute's Institutional Review Board approved this study.

During the ClinSeq enrollment visit participants completed a baseline survey about their intentions to receive genotype results from WGS followed by an informed consent discussion with a genetic counselor. It entailed WES/WGS description, type of results that can be generated, choice to receive individual results over time, limitations in interpreting data, lack of reporting of uninterpretable information and absent pathogenic variants, and the length of time before receiving results. Emphasis was placed on the significant limitations of our ability to interpret data from WES/WGS and the degree and scope of uncertainty. Following the session, participants completed a second survey of the same key variables.

The surveys included use of open-ended questions and validated scales that were chosen based on the health-related theory of planned behavior. $^{22}$ Participants were asked their general preferences and reasons for receiving results. Participant attitudes, subjective norms and intentions to receive sequence results were assessed following description of four distinct categories of findings. The four categories included variants that could predispose to preventable or treatable conditions (category A); variants that could predispose to conditions that are not amenable to prevention or treatment (category B); variants that establish carrier status (category $\mathrm{C}$ ); and variants of uncertain clinical significance (category D).

\section{Open-ended questions}

In the pre-consent survey, participants were asked: 'Do you want to learn about your results from genome sequencing? (Yes, No, Uncertain). What are your reasons for wanting, not wanting, or being uncertain about learning your results from genome sequencing?' These questions were followed by two additional questions, which probed about personal and family history of disease: 'Is there anything about your health history or the health history of your 
relatives that makes you want to learn about your results from genome sequencing? (Yes, No). If yes, what part of your health history or your family health history makes you want to learn about these results?'

Responses to the open-ended questions were read for content and an initial codebook was developed. The codebook was revised for content validity through an iterative process involving discussions amongst the research team until the coding scheme was determined to be concise and robust. Using NVIVO 8 QSR (http://www. qsrinternational.com/default.aspx), a qualitative analysis software package, the responses were analyzed by two independent coders to ensure coding consistency. Inter-coder reliability was determined to be $99 \%$ for the question regarding their reasons to learn results, and 99\% for the question regarding their personal and family health history. Discrepancies in the coding were discussed and reconciliation was achieved. Analysis was based upon consensus codes. Data saturation was facilitated by the large sample size.

\section{Measures}

Attitudes toward learning findings from sequencing were measured using a six-item scale modeled on previously published scales. ${ }^{23-26}$ Participants were asked to rate their response to: 'for me, learning such a result would be' by rating 1-7 on six items anchored by 'a bad thing-not a bad thing', 'not beneficial-beneficial', 'harmful-not harmful', 'not a good thing-a good thing', 'not worthwhileworthwhile', 'unimportant-important'. Ratings were averaged and Cronbach alpha scores ranged from 0.88 to 0.96 for the four result categories.

Perceived social norms assessed the perceptions of the views of valued others. A scale that has been used in many other studies asked participants to rate from 1 'definitely no' to 5 'definitely yes' the statements 'The following people think that I should learn about such a result: my partner, my doctor, my closest friends, my siblings, my children. ${ }^{23}$ Ratings were averaged and Cronbach alpha scores ranged from 0.82 to 0.93 across result categories.

Intentions to learn results from WGS were measured by the sum of two questions: 'I intend to learn about such a result': definitely yes, probably yes, not sure, probably not, definitely not, and 'How likely is it that you will choose to learn about such a result?': extremely unlikely to extremely likely. The range of responses is $0-12$. Cronbach alpha scores ranged from 0.58 to 0.90 .

Statistical analyses were done using SPSS 19.0. ANOVAs were used to test for differences among the means in the key variables. Spearman correlations were used to determine relationships among key variables.

\section{RESULTS}

\section{Sample characteristics}

This study population was collected after that of a prior assessment. ${ }^{18}$ It was consecutive with a $100 \%$ response rate given that it was presented as part of the study protocol. The characteristics of the 311 ClinSeq participants who completed the intention surveys did not differ significantly from those in the larger cohort (see Table 2). The population is primarily white, well educated and earning a high income. Participants share characteristics with early adopters to other new technologies as discussed in a prior publication. ${ }^{18}$ Only baseline (pre-consent) data is presented; there were no significant differences between variables pre- to post-consent. The baseline survey contained the open-ended questions. By using the baseline quantitative data, we report an analysis of a data set collected at the same time point.
Table 2 Participant characteristics

\begin{tabular}{|c|c|c|}
\hline & $\begin{array}{l}\text { ClinSeq cohort } \\
\qquad \mathrm{N}=909\end{array}$ & $\begin{array}{l}\text { Intentions study } \\
\qquad \mathrm{N}=311\end{array}$ \\
\hline $\begin{array}{l}\text { Mean age (years) } \\
\text { Females }\end{array}$ & $\begin{array}{l}56.6 \\
455\end{array}$ & $\begin{array}{l}55.8 \\
128^{*}\end{array}$ \\
\hline $\begin{array}{l}\text { Race } \\
\text { White (\%) } \\
\text { Black (\%) } \\
\text { Asian (\%) }\end{array}$ & $\begin{array}{l}780(85.8) \\
34(3.7) \\
45(4.9)\end{array}$ & $\begin{array}{c}253(81.4)^{*} \\
16(5.1)^{*} \\
19(6.1)^{*}\end{array}$ \\
\hline $\begin{array}{l}\text { Education } \\
\text { Less than college (\%) } \\
\text { College and higher }(\%)\end{array}$ & $\begin{array}{l}120(13.2) \\
667(73.4)\end{array}$ & $\begin{array}{c}49(15.8) \\
253(81.4)\end{array}$ \\
\hline $\begin{array}{l}\text { Annual Income } \\
\text { Less than } \$ 100000(\%) \\
\$ 100000 \text { or more }(\%)\end{array}$ & $\begin{array}{l}198(21.8) \\
568(62.5)\end{array}$ & $\begin{array}{c}68(21.9) \\
227(73.0)\end{array}$ \\
\hline
\end{tabular}

${ }^{*} P<0.05$ using a one sample $Z$-test comparison of proportions.

\section{Open-ended responses}

When asked whether participants wished to learn results, 294 responded that they did and 6 were uncertain. Remarkably, none of the participants ticked no. When asked why, a majority of 249 respondents expressed a general interest in prevention, stating that by receiving results they may be better equipped to prevent the onset of a disease that they are at a greater risk of developing.

To learn if I have any variants that I can act upon to improve my health' (F/61) 117091 '[To take] preventative action to hopefully reduce [the] probability or delay [the] onset of potential disease' (M/56) 157974.

Some $(N=70)$ respondents specifically expressed a prevention-related intent to alter their medical management or to improve their diet and exercise habits.

'Given my genes, is there any medication and/or supplements that will contribute to healthy aging?' (F/62) 150667 '[To learn] if there's a way I should be doing anything differently-diet, exercise, medications, etc.- to keep myself healthy' (F/50) 102040.

About a third $(N=89)$ of participants conveyed a general desire to know health information. Respondents in this group expressed a belief that all knowledge is positive.

'Knowledge is power.' (F/55) 173946 'I want to know as much about myself as possible.' (F/62) 185955 'I'd rather know than not know.' (M/59) 144842 'Would not have entered study if I wasn't interested in results.' (M/57) 107559.

Another third $(N=85)$ of participants wished to know their results specifically to inform their children and family.

'... I owe it to my daughter to inform her of anything that may also impact her.' (M/57) 155489.

Asked whether their personal or family history motivates their interest in results, 299 of 306 ticked yes. When asked what aspects of their family history led participants to want to learn results, most $(N=204)$ responded with a specific disease or health condition of concern. As ClinSeq recruited participants both affected by and at risk for coronary artery disease, it is not surprising that a majority identified heart disease as one of the conditions in their family. Many 
Table 3 Means and SD for attitudes, social norms and intentions

\begin{tabular}{lcc}
\hline Variables & $\mathrm{N}$ & Mean (SD) \\
\hline Attitudes & 305 & \\
$\quad$ Category A & 304 & $6.81(0.43)$ \\
Category B & 303 & $6.12(1.27)$ \\
Category C & 302 & $6.67(0.74)$ \\
Category D & & $5.98(1.39)$ \\
ANOVA & & $F=46.97^{\mathrm{a}}$ \\
Social norms & 292 & \\
Category A & 285 & $4.50(0.62)$ \\
Category B & 288 & $4.13(0.87)$ \\
Category C & 291 & $4.01(0.67)$ \\
Category D & & $4.02(0.94)$ \\
ANOVA & & $F=29.84^{\mathrm{a}}$ \\
Intentions & & \\
Category A & 284 & $11.84(0.58)$ \\
Category B & 279 & $11.02(1.94)$ \\
Category C & $11.69(1.02)$ \\
Category D & 279 & $10.74(2.18)$ \\
ANOVA & 279 & $F=31.65^{\mathrm{a}}$ \\
\hline
\end{tabular}

aCorrelation is significant at $P<0.01$.

participants also noted cancer as a concern in their family. A smaller group of participants $(N=47)$ noted a specific disease or health condition that affects them, most often heart disease.

\section{Attitudes, social norms and intentions}

Mean attitude scores among the four result categories ranged from 5.98 to 6.81 on a scale from 1 to 7 . Social norms scores ranged from 4.02 to 4.50 on a scale from 1 to 5 (see Table 3). Intentions were similarly high, ranging from 11.02 to 11.84 on a scale from 0 to 12 . Differences among the means were statistically significant with responses to categories A (treatable or preventable health information) and $\mathrm{C}$ (carrier information) being highest and most similar and statistically distinct from categories B (untreatable or preventable health information) and D (uninterpretable information).

Contrary to our hypothesis, attitudes toward receiving results for a condition that may be treated or prevented were most similar for results that identify carrier status. As hypothesized, there was significantly less interest in variants of unknown significance, but not to the degree anticipated. Attitudes and social norms were significantly correlated in all four categories of results and each was independently correlated with intentions to receive results (see Table 4).

Regression models for intentions were built using attitudes and social norms and any sociodemographic factors that were correlated in the bivariate analyses (see Table 5). Attitudes and social norms together accounted for $4-16 \%$ of the variation across the four categories. Sociodemogaphic factors fell out of the models for all four categories of results.

\section{DISCUSSION}

Our findings elucidated the preferences of a representative sub-sample of the ClinSeq cohort with respect to the receipt of sequencing results, and show that they broadly value the anticipated information. There were no statistically significant differences in the means between $\mathrm{T} 1$ and T2 for all three key variables. This finding suggests that participants enrolled with enthusiasm for receiving results and discussion of the limitations on our ability to interpret the information had little to no effect in changing their expectations.

Attitudes toward receipt of information and perceptions of the views of valued others were highly positive for all four categories of information, including those results which cannot be interpreted. It is
Table 4 Spearman correlation matrix of attitudes, social norms and intentions

\begin{tabular}{|c|c|c|c|}
\hline & Attitudes & Social norms ${ }^{\mathrm{a}}$ & Intentions ${ }^{\mathrm{a}}$ \\
\hline \multicolumn{4}{|l|}{ Category A } \\
\hline Attitudes & - & 0.328 & 0.2285 \\
\hline Social norms & - & - & 0.325 \\
\hline \multicolumn{4}{|l|}{ Category B } \\
\hline Attitudes & - & 0.583 & 0.604 \\
\hline Social norms & - & - & 0.525 \\
\hline \multicolumn{4}{|l|}{ Category C } \\
\hline Attitudes & - & 0.381 & 0.396 \\
\hline Social norms & - & - & 0.229 \\
\hline \multicolumn{4}{|l|}{ Category D } \\
\hline Attitudes & - & 0.546 & 0.601 \\
\hline Social norms & - & - & 0.569 \\
\hline
\end{tabular}

aCorrelation is significant at $P<0.01$.

Table 5 Logistical regression on intentions

\begin{tabular}{lccc}
\hline & Estimate/SE & t-value & Pr>|t| \\
\hline Logistical regression-intentions (category A) & & \\
Attitudes & $0.163 / 0.083$ & 1.96 & 0.05 \\
Social norms & $0.212 / 0.083$ & 2.57 & 0.01 \\
& & \\
Logistical regression-intentions (category B) & & \\
Sex & $0.357 / 0.160$ & 2.23 & 0.03 \\
Income (dichotomized) & $-0.321 / 0.184$ & -1.74 & 0.08 \\
Attitudes & $0.599 / 0.098$ & 6.10 & $<0.0001$ \\
Social norms & $0.604 / 0.153$ & 3.96 & $<0.001$ \\
& & & \\
Logistical regression-intentions & $($ category C) & & \\
Income (dichotomized) & $-0.181 / 0.106$ & -1.70 & 0.09 \\
Attitudes & $0.418 / 0.070$ & 5.94 & $<0.001$ \\
Social norms & $0.179 / 0.074$ & 2.42 & 0.02 \\
& & & \\
Logistical regression-intentions & $($ category D) & & \\
Sex & $0.227 / 0.172$ & 1.32 & 0.19 \\
Income (dichotomized) & $-0.354 / 0.211$ & -1.68 & 0.09 \\
Education & $0.185 / 0.118$ & 1.57 & 0.12 \\
Race & $0.284 / 0.215$ & 1.32 & 0.19 \\
Attitudes & $0.611 / 0.087$ & 7.03 & $<0.0001$ \\
Social Norms & $1.083 / 0.119$ & 9.14 & $<0.0001$ \\
& & &
\end{tabular}

not surprising that these variables were significantly correlated with intentions that were also high, reflecting preferences to receive all types of genetic test information. Although we found statistically significant differences in the mean scores for attitudes, social norms and intentions across the four scenarios, the responses were sufficiently positive that these differences may have limited clinical relevance in predicting selection among the four categories in the future. We can only speculate why attitudes and intentions were highest and most similar between results that were described as actionable and those that reveal carrier status. Our open-ended responses suggest that information about risks to future generations may be viewed by the ClinSeq participants to be as valuable as information about personal health risk that can be mitigated.

Taken together, our results reflect the participants' ability to discriminate among the types of results, and their desire to learn all of them. When asked why, participants identified use of the information in health promotion, disease prevention and less often, intent to change their lifestyle or medical management in response to the information. Collectively, these responses reflect their confidence in the usefulness of sequence information (a concept referred to as response efficacy), even information that is currently not interpretable. Our findings are consistent with a study of intentions to receive results from GWAS analysis for eight common health conditions. ${ }^{27}$ 
Response efficacy was found to significantly predict attitudes toward receiving results and attitudes explained a significant amount of the variance in intentions to undergo testing. Neither the present study nor that of Wade et al ${ }^{27}$ identified the source of significant response efficacy. Additional research is needed to understand how much confidence in the usefulness of the information is driven by the ways studies are introduced and how much is because of prior assumptions and expectations by participants. In the present study, the data were gathered before participating in the process of giving consent to participate in ClinSeq, lending support to an argument that participants entered the study with high intentions to receive all types of results from WGS.

Our prior study of expectations and motivations to participate in ClinSeq showed that half of the participants were motivated to learn personal health information. Thus, it is not surprising that this sample from the ClinSeq cohort conveyed confidence in their ability to use sequence information to maximize their health. For us as investigators, it is important to consider how to manage these expectations. Although ClinSeq participants will, over time, decide to learn information, currently there is limited evidence to guide them on prevention of future disease. Furthermore, regardless of their good intentions and receipt of individualized risk information, it is difficult for most people to change their lifestyle behaviors in a sustained way to achieve positive health outcomes. ${ }^{28}$

Importantly, our findings inform the discussion of the personal utility of sequence information, alongside clinical utility, in shaping guidelines for return of results. These participants wanted to know and saw value in the discovery of the information that may tell them more about themselves. This was both due to the value assigned by participants to potential genetic information, and to the hope that it could be put to good use in helping them or their relatives to live healthier lives.

\section{Limitations}

The ceiling effects seen in our key variables suggest an overall high level of enthusiasm for receipt of results, but the lack of variance in our outcome measure limits our ability to interpret the relative role of attitudes and social norms in determining intentions to receive results. The ClinSeq cohort is not representative of the general population. Yet participants do share characteristics with early adopters of technology.

\section{CONCLUSION}

The current limitations of WGC are challenging to balance with the hope and expectations of recipients of sequence information. As investigators proceed with WGS studies, there is an ongoing need to involve participants in the evolution of this new technology to understand their experiences and to temper some of their expectations that may be premature or unrealistic. Just as importantly, development of more robust, efficient and comprehensive bioinformatic analyses for the clinical interpretation of variants is critical in meeting what is clearly a great desire for, and an optimistic view of, genomic information among highly motivated research participants.

\section{CONFLICT OF INTEREST}

The authors declare no conflict of interest.

\section{ACKNOWLEDGEMENTS}

This research was supported by the Intramural Research Program of the National Human Genome Research Institute.

1 Singleton AB: Exome sequencing: a transformative technology. Lancet Neurol 2011; 10: $942-946$.

2 Torkamani A, Scott-Van Zeeland AA, Topol EJ, Schork NJ: Annotating individual human genomes. Genomics 2011; 98: 233-241.

3 Wolf SM, Crock BN, Van Ness B et al: Managing incidental findings and research results in genomic research involving biobanks and archived data sets. Genet Med 2012; 14: 361-384.

4 Ferriere M, Van Ness B: Return of individual research results and incidental findings in the clinical trials cooperative group setting. Genet Med 2012; 14: 411-416.

5 Fullerton SM, Wolf WA, Brothers KB et al: Return of individual research results from genome-wide association studies: experience of the Electronic Medical Records and Genomics (eMERGE) Network. Genet Med 2012; 14: 424-431.

6 McGuire AL, Lupski JR: Personal genome research: what should the participant be told? Trends Genet 2010; 26: 199-201.

7 Dizikes P: Gene information opens new frontier in privacy debate. Boston Globe 2007. http://www.boston.com/news/globe/health_science/articles/2007/09/24/gene_ information_opens_new_frontier_in_privacy_debate/.

8 Levy S, Sutton G, Ng PC et al: The diploid genome sequence of an individual human. PLOS Biol 2007; 5: 2113-2144.

9 Biesecker LG, Mullikin JC, Facio FM et al: The ClinSeq Project: piloting large-scale genome sequencing for research in genomic medicine. Genome Res 2009; 19: 1665-1674

10 Bookman EB, Langehorne AA, Eckfeldt JH et al: Reporting genetic results in research studies: Summary and recommendations of an NHLBI Working Group. Am J Med Genet 2006; 140A: 1033-1040.

11 Fabsitz RR, McGuire A, Sharp RR et al: Ethical and practical guidelines for reporting genetic research results to study participants: Updated guidelines from a national heart, lung, and blood institute working group. Circ Cardiovasc Genet 2010; 3 : 574-580.

12 Wolf SM, Lawrenz FP, Nelson CA et al: Managing incidental findings in human subjects research: analysis and recommendations. J Law Med Ethics 2008; 36: 219-248.

13 Kohane IS, Taylor PL: Multidimensional results reporting to participants in genomic studies: Getting it right. Sci Trans/ Med 2010; 2: 37cm19.

14 Dressler LG: Disclosure of research results from cancer genomic studies: state of the science. Clin Cancer Res 2009; 15: 4270-4276.

15 Ravitsky $\mathrm{V}$, Wilfond BS: Disclosing individual genetic results to research participants. Am J Bioethics 2006; 6: 8-17.

16 Kaufman D, Murphy J, Scott J, Hudson K: Subjects matter: a survey of public opinions about a large genetic cohort study. Genet Med 2008; 10: 831-839.

17 Bollinger JM, Scott J, Dvoskin R, Kaufman D: Public preferences regarding the return of individual genetic research results: findings from a qualitative focus group study. Genet Med 2012; 14: 451-457.

18 Facio FM, Brooks S, Loewenstein J, Green S, Biesecker LG, Biesecker BB: Motivators for participation in a whole-genome sequencing study: implications for translational genomics research. Eur J Hum Genet 2011; 19: 1213-1217.

19 Berg JS, Khoury MJ, Evans JP: Deploying whole genome sequencing in clinical practice and public health: meeting the challenge one bin at a time. Genet Med 2011; 13: 499-504.

20 Street Jr. RL, Elwyn G, Epstein RM: Patient preferences and healthcare outcomes: an ecological perspective. Expert Rev Pharmacoecon Outcomes Res 2012; 12: 167-180.

$21 \mathrm{Xu}$ B, Roos JL, Dexheimer P et al: Exome sequencing supports a de novo mutational paradigm for schizophrenia. Nat Genet 2011; 43: 864-868.

22 Ajzen I: Attitudes, Personality and Behaviour. Milton Keynes: Open university Press, 1991.

23 Dormandy E, Hankins M, Marteau T: Attitudes and uptake of a screening test: the moderating role of ambivalence. Psychol Health 2006; 21: 499-511.

24 Biesecker LG: Opportunities and challenges for the integration of massively parallel genomic sequencing into clinical practice: lessons from the ClinSeq project. Genet Med 2012; 14: 393-398.

25 Solomon BD, Hadley DW, Pineda-Alvarez DE et al: Incidental medical information in whole-exome sequencing. Pediatrics 2012; 129: e1605-e1611.

26 Montenegro G, Powell E, Huang J et al: Exome sequencing allows for rapid gene identification in a Charcot-Marie-Tooth family. Ann Neurol 2011; 69: 464-470.

27 Wade $\mathrm{CH}$, Shiloh S, Woolford SW et al: Modelling decisions to undergo genetic testing for susceptibility to common health conditions: an ancillary study of the Multiplex Initiative. Psychol Health 2011; 27: 430-444.

28 McBride CM, Bowen D, Brody LC et al: Future health applications of genomics: priorities for communication, behavioral, and social sciences research. Am J Prev Med 2010; 38: 556-565. 